\title{
The impact of COVID-19 triggered changes to instruction and assessment on university students' self-reported motivation, engagement and perceptions
}

\author{
Lia M. Daniels ${ }^{1}$ (D) Lauren D. Goegan ${ }^{1}$ (D) Patti C. Parker ${ }^{1}$
}

Received: 25 September 2020 / Accepted: 22 January 2021 / Published online: 16 February 2021

(c) The Author(s), under exclusive licence to Springer Nature B.V. part of Springer Nature 2021

\begin{abstract}
During the northern hemisphere Winter 2020 academic term, university students had to adjust to remote learning in response to the COVID-19 pandemic. This abrupt change provided a unique opportunity to examine students' motivation, engagement and perceptions of success and cheating under two learning conditions, namely traditional and remote. We used a single survey to collect retrospective selfreport data from a convenience sample of Canadian undergraduate students $(n=98)$ about their motivation, engagement and perceptions of success and cheating before COVID-19 and then in remote learning. Students' achievement goals, engagement and perceptions of success all significantly decreased, while their perceptions of cheating increased. Moreover, we used regression analyses to examine associations amongst achievement goals and engagement, perceptions of success and cheating concerns. Mastery-approach goals were positively associated with more engagement and higher perceptions of success. Achievement goals were unrelated to cheating. Students in large classes and who were originally concerned about cheating became more concerned about cheating in remote learning conditions. Our study provides information to researchers and instructors about how achievement goals relate to student outcomes across learning conditions. By extension, we provide timely recommendations for instructors as they continue to wrestle with how to deliver their courses during the COVID-19 pandemic.
\end{abstract}

Keywords Motivation - Achievement goals · Engagement - Success · Cheating · Undergraduates

Lauren D. Goegan

goegan@ualberta.ca

Lia M. Daniels

lia.daniels@ualberta.ca

Patti C. Parker

pparker@ualberta.ca

1 Department of Educational Psychology, University of Alberta, Edmonton, AB, Canada 


\section{Introduction}

During the Winter 2020 academic term, universities across the globe were required to make changes to their courses for students. Seemingly overnight, instructors moved their instructional and assessment practices to remote online delivery. This abrupt shift provided researchers with an unintended unique opportunity to examine student motivation for their courses under two different learning conditions. Understanding the changes to student motivation, engagement and perceptions of success and cheating following the transition to remote delivery is important for two reasons. First, it seems at least for the near future, more courses will continue to be delivered remotely even though instructors and students may desire to return to face-to-face instruction (Hyslop 2020). As such, the implications of remaining in a delivery style that is contrary to what is desired for student motivation is timely. Second, assessment practices online are often considered to be rife with opportunities for cheating (Miller and Young-Jones 2012) and identifying relationships between motivation and cheating can provide a novel avenue by which instructors can try to prevent academic dishonesty. Therefore, the purpose of this study was to examine students' achievement goals, engagement and perceptions of cheating and success under these two different learning conditions: face-to-face traditional class structure typical prior to COVID-19 and the remote online class structure that emerged to manage the public health risks.

\section{Theoretical framework: achievement goal theory}

We situate our research within the $2 \times 2$ version of achievement goal theory ${ }^{1}$ (Elliot and McGregor 2001). Researchers use Achievement Goal Theory to examine student motivation by considering the goals students have related to completing a task (Rawsthorne and Elliot 1999; Senko and Dawson 2017). Within this theory, achievement goals are conceptualized across two dimensions: competence and valence (for review: Elliot 1999; Elliot and McGregor 2001; Van Yperen et al. 2014). Competence is defined as either demonstrating competence relative to others, referred to as performance goals, or as demonstrating competence in terms of task mastery (mastery goals). Mastery goals have often been associated with positive learning processes and outcomes, including positive emotions, interest, persistence, effective self-regulation and learning strategies (for review see Senko and Dawson 2017).

The valence dimension distinguishes between approach and avoidance motivation (Elliot 1999; Elliot and Murayama 2008; Van Yperen et al. 2014). Approach motivation is defined as behaviour that is directed towards a positive outcome, such as learning something new. Conversely, avoidance motivation is defined as behaviour that is directed away from a negative outcome, such as failing a test. Avoidance goals are associated with maladaptive outcomes such as negative emotions, poor learning strategies and more openness to cheating (Senko and Dawson 2017), while approach goals are associated with higher academic achievement (Huang 2012).

\footnotetext{
1 Achievement Goal Theory has identified various achievement goal arrangements. We have selected the $2 \times 2$ design because if its widespread use in the literature.
} 
Moreover, approach goals have been positively associated with performance attainment in various domains including education, work and sports, whereas avoidance goals have a negative relationship with performance across domains (Van Yperen et al. 2014). Therefore, four achievement goals are identified, mastery-approach (MAP), mastery-avoidance (MAV), performance-approach (PAP) and performanceavoidance (PAV).

\subsection{Student engagement}

Student engagement is a multidimensional construct with many operationalizations. We use Fredricks and colleagues' (2004) framework that includes three components: (a) behavioural, (b) emotional and (c) cognitive. Behavioural engagement includes various student actions, such as effort, consistently completing coursework, participation and positive conduct like following the expectations for a course (Appleton et al. 2008; Daniels et al.2016; Sun and Rueda 2012). Emotional engagement, sometimes referred to as affective engagement (Appleton et al. 2008), includes students' feelings or attitudes towards their course. These feelings tend to vary from unpleasant feelings like boredom with the coursework to more pleasant feelings like interest in the tasks assigned. Cognitive engagement involves the internal thought processes involved in a student's coursework. For example, students are considered cognitively engaged when they deliberately invest cognitive resources to understand the ideas or concepts required by the course (Fredricks et al. 2004). Cognitive engagement could include looking for additional resources to aid understanding, asking self-directed questions, or discussing the content with people outside of class (Daniels et al. 2016; Sun and Rueda 2012). Alternatively, researchers describe cognitive engagement in terms of the cognitive processes required for a task, such as problem-solving, positive coping strategies, or a desire to learn (Appleton et al. 2008; Connell and Wellborn 1991).

The connection between students' goals and engagement has been investigated by various researchers (Gonida et al. 2009; Meece et al. 1988). For example, Shih (2008) examined achievement goals and behavioural and emotional engagement. Overall, MAP goals were associated with positive behavioural engagement such as higher levels of involvement, persistence and participation, while PAV goals were associated with more avoiding behaviours. Moreover, MAP goals were associated with higher levels of curiosity, enjoyment and lower levels of anxiety and boredom and PAV goals positively predicted anxiety and boredom. These results are consistent with the research of Sideridis and Kaplan (2011) who determined that persistence, representing a behavioural aspect of engagement, was positively associated with mastery-oriented students, as they persisted longer than students with PAP and PAV goals. Moreover, Daumiller and colleagues (2020) found that learning-approach goals, consistent with MAP goals, lead to more learning engagement operationalized as elaboration and intensity (i.e., how deeply the content is engaged with), whereas work-avoidance goals had a negative relationship with these engagement variables. The associations between achievement goals and behavioral, emotional and cognitive engagement in traditional learning conditions have clear 
patterns; however, there is no evidence on how these relationships may change following a spontaneous and perhaps unwelcome change in learning conditions.

\subsection{Cheating}

Conceptually, cheating is the antithesis of mastery forms of motivation and student engagement: mastery cannot be plagiarized and sincere engagement cannot be faked. Indeed, Pulfrey and colleagues (2019) suggest that MAP goals are counterintuitive to cheating behavior, thereby explaining why researchers have focused their investigation on the relationship between performance goals and students' cheating behaviors (Murdock and Anderman 2006). Some researchers show that performance goals are positively associated with cheating behaviour (e.g., Van Yperen et al. 2011), while others find no relationship between performance goals and cheating (e.g., Murdoch et al. 2001; Niya et al. 2008). To shed some light on these differences, Daumiller and Janke (2019), propose that cheating is also dependent on how performance is evaluated. In their experiment, the emphasis was placed on either process-based evaluation standards, that is, the strategies students used to solve the question, versus results-based evaluation standard, where achieving the correct answer was most important. They determined that students were more likely to cheat when they had appearance goals, which are consistent with performance goals and when the focus was on results-based evaluation.

In typical learning conditions, most university courses tend to use result-based evaluation (e.g., Yüksel and Gündüz 2017). However, some institutions changed this focus when instruction and assessment moved into remote delivery because of the public health restrictions resulting from the COVID-19 pandemic. As a case in point, the University of Alberta replaced their letter grade system with a credit/ no credit system (CR/NCR) for the Winter 2020 semester. Similar decisions were made at other institutions, many of which allowed students to choose between a letter grade and indication of credit (Fung 2020).

Concern for increased cheating under remote delivery was warranted because students report being almost four times more likely to be dishonest in online courses (42\%) than in-person courses (10\%) (Watson and Sottile 2010). Likewise, King and Case (2014) found that not only was the percentage of students who admitted to academic cheating activity increasing over a five-year period, but almost 3 in 4 students $(74 \%)$ felt that it was either very easy or somewhat easy to cheat on an online exam. None of this research, however, utilized a theoretical framework such as achievement goal theory to contextualize cheating in light of student motivation. As such, the shift in the format of instruction and assessment as a result of the COVID19 pandemic provided an opportunity to carefully consider relationships amongst achievement goals and cheating across these two different learning conditions.

\subsection{Academic success}

Regardless of whether courses occur in-person or online, students, instructors and other educational stakeholders care about students' academic success. Perhaps not 
surprisingly, grades and grade-point averages (GPA) are the most common indicators of success (Lounsbury et al. 2009; York et al. 2015). However, researchers suggest that there are many other indicators of academic success, including the learning of skills or knowledge and student satisfaction (Goegan and Daniels 2019; York et al. 2015). At the same time that implementation of a CR/NCR grading system for the Winter 2020 term helped lessen concerns related to cheating, it simultaneously removed the most traditional indicator of success. As a result, perceptions of success quickly took on a new priority as students reached their own, grade-free, conclusions about success-many of which may have been influenced by their achievement goals. Indeed, the positive relationship between approach goals and both objective (e.g., Huang 2012) and subjective indicators of academic achievement (e.g., Daniels et al. 2008) is well established in the literature. Building on this, we were interested in the relationship between achievement goals and students' perceptions of their success under these two learning conditions.

\subsection{The current study}

Utilizing achievement goal theory as our theoretical model (Elliot and Murayama 2008), we examined the connections between students' achievement goals and their course engagement and perceptions of cheating and success under two naturally occurring learning conditions. Students participated in traditional learning conditions involving face-to-face instruction, in-person assessment and a results-based normative grading policy from January 7, 2020 to March 12, 2020. As a result of the public health measures associated with COVID-19, beginning March $17^{\text {th }}$ students were automatically shifted into remote learning conditions involving online instruction, remote assessment and a CR/NC grading policy. Our two research questions were as follows: (a) Did students' motivation, engagement and perceptions of cheating and success change across the two learning conditions? and (b) Do achievement goals differently predict students' engagement and perceptions of cheating and success across the two conditions? We expected MAP goals to sustain engagement, prevent cheating and increase perceptions of success because of their intrapersonal standard. We expect the competitive nature of PAP goals to have the opposite effect. We expect that avoidance goals may have a possible beneficial function as students seek to "salvage" their learning under unprecedented learning conditions.

\section{Method}

We used a single-administration survey to collect students' retrospective and current appraisals of achievement goals, engagement and perceptions of cheating and success anchored around the changes to learning conditions triggered by COVID-19.

\subsection{Procedures}

In May of 2020, we posted a link to a questionnaire on multiple social media platforms including Facebook, Reddit and Twitter targeting students at our 
postsecondary institution. Information about the questionnaire was also included in the Students Digest, a weekly email sent to all registered students on campus that includes information such as current events, important deadlines and opportunities to participate in research. The questionnaire was live from May 6 to 15, 2020. After clicking the link, students viewed an informational letter outlining the details of the study. Consent was implied by students clicking "Next" and by completion of the questionnaire which required approximately five minutes. Participants completed all items twice: once retrospectively indicating their goals, engagement and perspectives during the traditional learning conditions (henceforth, Condition 1, or C1) and again to indicate their goals, engagement and perspectives during the remote learning conditions (henceforth, Condition 2, or C2). This set of instructions served as a within person naturally occurring manipulation. To thank the students for their participation, they selected for the researchers to make a $\$ 1$ donation to either the Student Mental Health Fund or the Campus Food Bank. Recognizing the stresses associated with COVID-19, we provided links to health and wellness supports at the end of the questionnaire. Ethics approval was obtained from the Human Ethics Research Office at the researchers' university.

\subsection{Participants}

Self-report data were collected from a convenience sample of 119 students from a midsize university in western Canada. The sample was then restricted to undergraduate students 31 years or younger. The final sample consisted of 98 students, 77 who identified as women, 18 men and 4 non-binary. The sample self-identified as predominantly Caucasian $(50.5 \%)$ and Asian $(27.3 \%)$. Students were from various faculties, with the top three being Arts (32.3\%), Science $(30.3 \%)$ and Education $(10.1 \%)$. Students identified their year in program, including 22 first-year, 30 second-year, 17 third-year, 23 fourth-year and 6 fifth-year or higher students.

\subsection{Measures}

\subsubsection{Demographic measures}

In order to describe the sample, we asked participants to indicate their gender, age, ethnicity, year in program and faculty.

\subsubsection{Focusing question}

Because motivation constructs and engagement tend to function in a domain-specific way, we asked participants to answer all survey items based on one specific course they took during the Winter 2020 academic term. They named the course and reported its class size. 


\subsubsection{Achievement goals}

Achievement goals were assessed using a 12-item scale by Elliot and Murayama (2008). The scale includes three items each to measure goals related to masteryapproach (MAP), mastery-avoidance (MAV), performance-approach, (PAP) and performance-avoidance (PAV). Participants responded to these items twice to measure their responses based on $\mathrm{C} 1$ (i.e., traditional learning conditions) and $\mathrm{C} 2$ (i.e., remote learning conditions). Students were asked: To what extent do you agree with the following statements? and responded on a scale from 1 (strongly disagree) to 5 (strongly agree). Higher scores indicated more agreement with the various subscales. Additional information including reliabilities and sample items are provided in Table 1.

\subsubsection{Student engagement}

Student engagement was assessed using a modified scale originally developed by Sun and Rueda (2012). The scale included items for behavioural, emotional and cognitive engagement in online classes. Similar to the achievement goal items, participants responded twice to indicate their perspectives on $\mathrm{C} 1$ and $\mathrm{C} 2$. We modified the items utilized by Sun and Ruede to fit these two learning conditions. Sample items and descriptive statistics are presented in Table 1. The scale includes five items for behavioural engagement (BE), seven items for emotional engagement, $(\mathrm{EE})$ and five items for cognitive engagement (CE). Students responded to items on a scale from 1 (strongly disagree) to 5 (strongly agree), with higher scores indicating more engagement on the various subscales.

\subsubsection{Cheating and success}

We used single items to measure students' perceptions of cheating and success in their course on a scale from 1 (strongly disagree) to 5 (strongly agree). To assess their perceptions about cheating in their course, students responded to the item: "I was concerned about students cheating in the class." To assess students' feelings of success, they responded to the item: "I felt successful in the class." Again, participants responded twice to indicate their perspectives for both $\mathrm{C} 1$ and $\mathrm{C} 2$ learning conditions.

\subsection{Plan of analysis}

We conducted our analyses in three stages. After examining the reliability of all subscales, we performed nine paired-samples $t$-tests to examine the four student achievement goals, three engagement scales and perceptions of cheating and success within students and across the two learning conditions. Second, we ran zero-order correlations for all variables. Third, we used five separate hierarchical regression analyses to test the relationship amongst achievement goals and the five criterion 


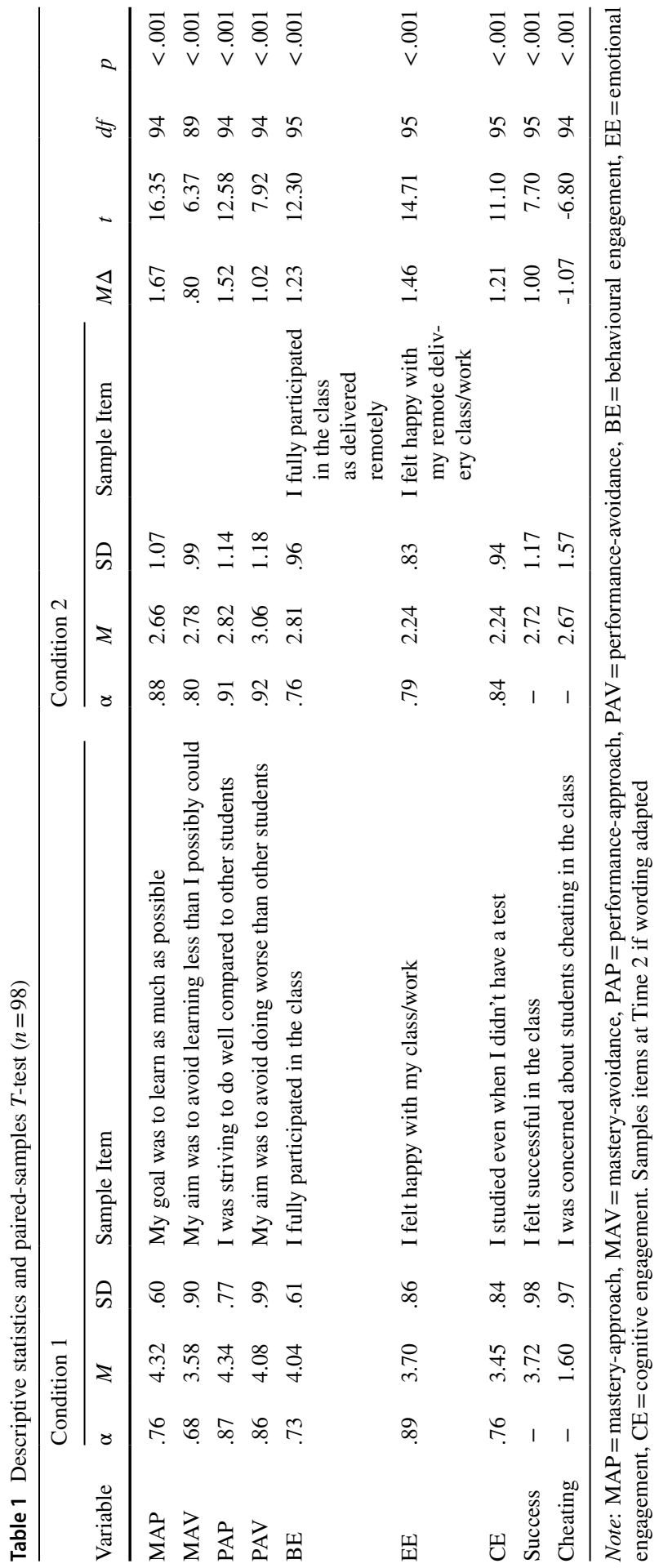


Table 2 Correlations between study variables. C1 below the diagonal and C2 above

\begin{tabular}{llllllllll}
\hline & 1 & 2 & 3 & 4 & 5 & 6 & 7 & 8 & 9 \\
\hline $1 . \mathrm{MAP}$ & - & $.58^{* * *}$ & $.41 * * *$ & .21 & $.56 * * *$ & $.44 * * *$ & $.69 * * *$ & $.36 * * *$ & .05 \\
2. MAV & $.42 * * *$ & - & .19 & .17 & $.46 * * *$ & $.31 * *$ & $.50 * * *$ & $.26 *$ & .01 \\
3. PAP & $.35 * * *$ & $.26 *$ & - & $.71 * * *$ & $.26 *$ & .13 & $.31 * *$ & $.32 * *$ & .22 \\
4. PAV & .13 & $.46^{* * *}$ & $.43 * * *$ & - & $.32 * *$ & .08 & .19 & $.39 * * *$ & .18 \\
5. BE & $.46 * * *$ & .19 & $.54 * * *$ & .21 & - & $.43 * * *$ & $.56 * * *$ & $.51 * * *$ & .08 \\
6. EE & $.57 * * *$ & $.28 * *$ & $.42 * * *$ & .20 & $.65 * * *$ & - & $.49 * * *$ & $.46 * * *$ & -.11 \\
7. CE & $.60 * * *$ & $.37 * * *$ & $.44 * * *$ & .13 & $.62 * * *$ & $.63 * * *$ & - & $.53 * * *$ & .05 \\
8. Success & $.30 * *$ & .08 & $.61 * * *$ & .12 & $.56 * * *$ & $.44 * * *$ & $.45 * * *$ & - & -.01 \\
9. Cheat & -.18 & -.11 & -.13 & -.16 & -.19 & -.16 & -.04 & -.05 & - \\
\hline
\end{tabular}

$* p<.025, * * p<.01, * * * p<.001 . \mathrm{MAP}=$ mastery-approach, MAV = mastery-avoidance, $\mathrm{PAP}=$ performance-approach, $\mathrm{PAV}=$ performance-avoidance, $\mathrm{BE}=$ behavioural engagement, $\mathrm{EE}=$ emotional engagement, $\mathrm{CE}=$ cognitive engagement

variables of behavioral, cognitive and emotional engagement, cheating and success. Specifically, in Step 1 we controlled for gender, age, year in program and number of students in the course. In Step 2 we added the measures of achievement goals for C1 and the score on the criterion variable for C1. In Step 3, we added the achievement goal for C2. This ordering of variables allowed us to explain students' engagement, cheating and success under $\mathrm{C} 2$, taking into account their scores at $\mathrm{C} 1$.

\section{Results}

\subsection{Paired samples $T$-test}

The results from the paired samples $t$-tests are included in Table 1 with an adjusted $p$ value to $\leqq 0.025$ to control for Type I error. Students' scores on all achievement goal and engagement variables decreased significantly across the two learning conditions. This decrease was most prominent for MAP goals, where on average, students decreased one and a half points on the 5-point likert scale. The most prominent decrease in terms of engagement was for emotional engagement, where students again decreased almost one and a half points on the 5-point likert scale. Students' reported more concerns with cheating across the two learning conditions and felt less successful.

\subsection{Correlation}

The correlations for variables reflecting $\mathrm{C} 1$ responses are presented below the diagonal in Table 2, while correlations reflecting $\mathrm{C} 2$ variables are presented above the diagonal. The correlations between the two formats are presented in Table 3. We note a number of important correlations here. Correlations between the engagement 
Table 3 Correlations between study variable at Time 1 and Time 2

\begin{tabular}{llllllllll}
\hline & MAP C2 & MAV C2 & PAP C2 & PAV C2 & BE C2 & EE C2 & CE C2 & Success C2 & Cheat C2 \\
\hline MAP C1 & $.41^{* * *}$ & $.28^{* *}$ & .07 & .01 & .16 & .08 & .21 & -.01 & .15 \\
MAV C1 & $.27 * *$ & $.21^{*}$ & .13 & .21 & .14 & -.01 & .15 & -.05 & .05 \\
PAP C1 & .04 & .01 & $.29 * *$ & $.36^{* * *}$ & .19 & -.08 & -.01 & .16 & $.30^{* *}$ \\
PAV C1 & -.11 & .03 & .18 & $.33^{* *}$ & .06 & -.05 & -.17 & .05 & .06 \\
BE C1 & .05 & .05 & -.10 & .05 & $.27 * *$ & .06 & .02 & .12 & .19 \\
EE C1 & $.31 * *$ & .22 & .09 & .10 & .15 & $.34 * *$ & .21 & .20 & .12 \\
CE C1 & $.28 * *$ & .16 & -.08 & .03 & .13 & .11 & $.28 * *$ & .13 & .10 \\
Success C1 & .03 & -.03 & .13 & $.23 *$ & $.24 *$ & .02 & .11 & $.30^{* *}$ & $.27 * *$ \\
Cheat C1 & .02 & -.01 & .05 & .08 & .07 & -.17 & .08 & -.05 & $.34 * *$ \\
\hline
\end{tabular}

$* p<.025, * * p<.01, * * * p<.001 . \mathrm{MAP}=$ mastery-approach, MAV = mastery-avoidance, $\mathrm{PAP}=$ performance-approach, $\mathrm{PAV}=$ performance-avoidance, $\mathrm{BE}=$ behavioural engagement, $\mathrm{EE}=$ emotional engagement, $\mathrm{CE}=$ cognitive engagement

scales were all positive under both learning conditions. Under $\mathrm{C} 1$, behavioural engagement had the strongest correlation with PAP goals, while for $\mathrm{C} 2$, the strongest correlation with behavioral engagement was MAP goals. Emotional and cognitive engagement had the highest correlation with MAP goals under both formats. The success item had the strongest correlation with performance-approach goals for $\mathrm{C} 1$ and PAV for $\mathrm{C} 2$. None of the predictor variables were significantly correlated with concerns about cheating.

\subsection{Regressions analyses for engagement}

All standardized beta weights from the regression analyses are presented in Table 4 for behavioral, emotional and cognitive engagement. To be consistent with the paired samples $t$-tests, we adjusted the $p$ value to $\leqq 0.025$ to control for Type I error.

\subsubsection{Behavioral engagement}

In terms of behavioural engagement, there were no significant relationships with any of the variables entered in Step $1, F(3,83)=2.02, p>0.025$. At Step 2, there were also no significant relationships between behavioral engagement at $\mathrm{C} 2$ and any of the variables entered including the $\mathrm{C} 1$ measure of behavioral engagement, $F(8,78)=2.29, p>0.025$. At Step $3, \mathrm{C} 2 \mathrm{MAP}$ goals significantly and positively predicted behavioural engagement at $\mathrm{C} 2$. This model explained $40 \%$ of the variance, $F(12,74)=5.78, p<0.001$. No other variables were significant at Step 3 .

\subsubsection{Emotional engagement}

Similar to behavioral engagement, there were no significant relationships with any of the variables entered into Step 1 of the model, $F(3,83)=3.04, p>0.025$. At Step 2 , emotional engagement at $\mathrm{C} 1$ significantly and positively predicted emotional 
Table 4 Regression analysis for engagement items at condition 2

\begin{tabular}{lllllllllll}
\hline $\begin{array}{l}\text { Predictor } \\
\text { variable }\end{array}$ & $\begin{array}{l}\text { Behavioural } \\
\text { engagement }\end{array}$ & $\begin{array}{l}\text { Emotional } \\
\text { engage- } \\
\text { ment }\end{array}$ & $\begin{array}{l}\text { Cognitive } \\
\text { engage- } \\
\text { ment }\end{array}$ & & & & & & & \\
Step 1 & Step 2 & Step 3 & Step 1 & Step 2 & Step 3 & Step 1 & Step 2 & Step 3 \\
\hline 1. Age & .19 & .25 & .13 & .10 & .10 & .04 & .24 & .26 & .21 \\
2. \# of Stu- & -.12 & -.17 & -.01 & -.10 & -.10 & -.01 & -.09 & -.11 & .03 \\
$\quad$ dents & & & & & & & & & \\
3. Year & .02 & -.01 & .01 & .20 & .14 & .14 & -.06 & -.07 & -.10 \\
4. MAP C1 & & .06 & -.16 & & -.11 & -.22 & & .10 & -.17 \\
5. MAV C1 & & .14 & -.05 & & .03 & -.10 & .25 & .05 \\
6. PAP C1 & & .29 & .15 & & -.17 & -.19 & .04 & -.04 \\
7. PAV C1 & & -.09 & .04 & & -.03 & .08 & & $-.33^{*}$ & -.19 \\
8. DV C1 & & .05 & .18 & & $.46^{* *}$ & $.40^{* *}$ & & .10 & .20 \\
9. MAP C2 & & & $.52^{* * *}$ & & & $.41^{* *}$ & & & $.47^{* * *}$ \\
10. MAV C2 & & & .17 & & & .04 & & & $.23 *$ \\
11. PAP C2 & & & -.10 & & & -.05 & & & .14 \\
12. PAV C2 & & & .20 & & & .08 & & & .01 \\
Adjusted $R^{2}$ & .03 & .11 & $.40^{* * *}$ & .07 & $.16^{* *}$ & $.27^{* * *}$ & .03 & $.13^{*}$ & $.50^{* * *}$ \\
\hline
\end{tabular}

Note: $* p<.025, * * p<.01, * * * p<.001, \mathrm{DV}=$ The associated Dependent Variable as measured at $\mathrm{C} 1$

engagement at $\mathrm{C} 2$. This model explained $16 \%$ of the variance, $F(8,78)=3.11$, $p=0.004$. No other variables were significant at Step 2. At Step 3, emotional engagement at $\mathrm{C} 1$ remained significant and MAP goals at $\mathrm{C} 2$ significantly and positively predicted emotional engagement at $\mathrm{C} 2$. No other variables were significant at Step 3. This model explained $27 \%$ of the variance, $F(12,74)=3.67, p<0.001$.

\subsubsection{Cognitive engagement}

Similar to above, there were no significant relationships with any of the variables entered into Step 1 of the model, $F(3,83)=1.74, p>0.025$. At Step 2, PAV goals at $\mathrm{C} 1$ significantly and negatively predicted cognitive engagement at $\mathrm{C} 2$. This model explained $13 \%$ of the variance, $F(8,78)=2.57, p=0.015$. At Step 3, PAV goals at $\mathrm{C} 1$ were no longer a significant predictor. Additionally, MAP and MAV goals at C2 significantly and positively predicted cognitive engagement. No other variables were significant at Step 3. This model explained $50 \%$ of the variance, $F(12,74)=8.27$, $p<0.001$.

\subsection{Regressions analyses for students perceptions}

All standardized beta weights from the regression analyses are presented in Table 5 for students' concerns for cheating and perceptions of success. 
Table 5 Regression analysis for success and cheating at Time 2

\begin{tabular}{|c|c|c|c|c|c|c|}
\hline \multirow[t]{2}{*}{ Predictor Variable } & \multicolumn{3}{|c|}{ Success } & \multicolumn{3}{|l|}{ Cheat } \\
\hline & Step 1 & Step 2 & Step 3 & Step 1 & Step 2 & Step 3 \\
\hline 1. Age & .15 & .13 & .04 & .08 & .13 & .17 \\
\hline 2. \# of Students & -.11 & -.16 & -.03 & $.46^{* * *}$ & $.38^{* * * *}$ & $.38^{* * * *}$ \\
\hline 3. Year & .02 & -.03 & .01 & .06 & .06 & .04 \\
\hline 4. MAP C1 & & -.07 & -.19 & & .11 & .09 \\
\hline 5. MAV C1 & & .02 & -.14 & & -.06 & -.06 \\
\hline 6. PAP C1 & & .04 & -.07 & & $.26^{*}$ & .23 \\
\hline 7. PAV C1 & & -.03 & .05 & & -.01 & -.02 \\
\hline 8. DV C1 & & $.32^{*}$ & $.31^{*}$ & & $.28^{* *}$ & $.28^{* *}$ \\
\hline 9. MAP C2 & & & $.40^{* *}$ & & & -.03 \\
\hline 10. MAV C2 & & & .12 & & & .03 \\
\hline 11. PAP C2 & & & -.13 & & & .27 \\
\hline 12. PAV C2 & & & $.35^{*}$ & & & -.09 \\
\hline Adjusted $R^{2}$ & .01 & .07 & $.30^{* * * *}$ & $.16^{* * *}$ & $.29^{* * * *}$ & $.30^{* * * *}$ \\
\hline
\end{tabular}

Note: $* p<.025, * * p<.01, * * * p<.001, \mathrm{DV}=$ The associated Dependent Variable as measured at $\mathrm{C} 1$

\subsubsection{Concerns for cheating}

At Step 1, the number of students in the course positively and significantly predicted concerns with cheating, wherein students were more concerned with cheating in large classes. The model accounted for $16 \%$ of the variance, $F(3,83)=6.59$, $p<0.001$. The number of students in the course remained a significant predictor in Step 2. Additionally, PAP goals at $\mathrm{C} 1$ and their concerns for cheating at $\mathrm{C} 1$ also positively and significantly predicted concerns for cheating at $\mathrm{C} 2$. The model accounted for $29 \%$ of the variance, $F(8,78)=5.28, p<0.001$. At Step 3 , the addition of $C 2$ achievement goals did not result in a significant increase in explained variance $R^{2}$ $\Delta=0.04, p=0.284$.

\subsubsection{Perceptions of success}

In terms of students' perceptions of success at $\mathrm{C} 2$, there were no significant relationships with any of the predictor variables entered in Step $1, F(3,83)=1.40$, $p>0.025$. At Step 2, students' perception of success at C2 was significantly and positively predicted by perception of success at $\mathrm{C} 1$. The model accounted for $7 \%$ of the variance, $F(8,78)=1.76, p>0.025$. This relationship between students' perceptions of success and C1 and C2 remained significant at Step 3. Moreover, MAP and PAV goals at $\mathrm{C} 2$ also significantly and positively predicted students' perceptions of success at $\mathrm{C} 2$. In total, the model accounted for $30 \%$ of the variance, $F(12,74)=4.98$, $p<0.001$. 


\section{Discussion}

The purpose of this research was to examine students' achievement goals and how they related to their engagement, concerns about cheating and perceived success under two learning conditions resulting from the measures implemented during the COVID-19 pandemic. In this discussion, we focus on how our findings can expand the current understanding of achievement goals under different learning conditions, in particular, when shifting to remote online delivery and a CR/NC grading system. Specifically, we attend to three findings with relevant theoretical and practical implications. First, we discuss how students' achievement goals, engagement and perceptions changed across the two learning conditions. Second, in line with much of the achievement goal theory literature we describe the importance of mastery-approach goals. Third, we highlight the unexpected relationship between performance-avoidance goals and success under remote learning conditions. In closing, we also discuss the limitations of our research and recommendations for future research.

\subsection{All self-report variables changed}

Based on the variables we collected, our results suggest that "everything" changed following the shift to remote learning conditions. We saw a uniform decrease in all four achievement goals and all three forms of engagement. Moreover, the $\mathrm{C} 1$ scores on achievement goals and engagement were correlated with $\mathrm{C} 2$ scores on the same measure, yet, they were not always the stronger correlations. This is highly uncommon from a measurement perspective in which the best predictor of a later variable tends to be an earlier score on that variable. Instead, our results highlight that the change in learning conditions had a meaningful impact on students' achievement goals and their self-reported engagement. One limitation of the current study is that we did not collect information about students' personal wellbeing or hardships related to COVID-19. There may have been many personal and health-related factors that exacerbated the effects of the remote learning condition. As instructors continue to design courses for remote delivery and particularly during COVID-19, they may want to keep in mind that these are not only novel instructional conditions but many life conditions may make it harder for students to pursue their achievement goals and engage as fully as they could have in more traditional learning conditions.

\subsection{Mastery-approach goals are important}

Despite the finding that MAP goals had the largest mean decrease from $\mathrm{C} 1$ to $\mathrm{C} 2$ in the paired-samples $t$-tests, they continued to significantly and positively predict four of our five outcome measures, suggesting their importance for all three types of student engagement and perceptions of success. This is consistent with previous research that highlights the positive outcomes associated with MAP goals (Huang 2012; Senko and Dawson 2017). This is encouraging for instructors to know that the benefits of MAP can be realized even at lower mean levels. It also suggests that instructors may want 
to be particularly mindful of cultivating and maintaining MAP goals in either learning condition as a means of supporting students' engagement and perceptions of success.

To aid instructors in support MAP goals in the classroom, we draw on the universal design for learning (UDL) guidelines. In particular, multiple means of engagement provide suggestions for recruitment of interest and sustaining effort and persistence (CAST, 2018), both of which are important for MAP goals. Indeed, recruiting interest can include providing students with choice and autonomy to support their engagement with the learner outcomes for the course. When students have a choice, they can pick topics or activities of interest to them, supporting not only their MAP goals but also their engagement, behaviorally, emotionally and cognitively. Indeed, research by Jang and colleagues (2016) found perceived autonomy support was associated with student engagement. When instructors move their courses online, this can open up a variety of online learning opportunities that students can choose from, which supports their goals of learning and understanding the course content.

Moreover, the UDL guidelines note the importance of optimizing relevance, value and authenticity (CAST 2018). This guideline highlights the importance of utilityvalue when it comes to motivation and engagement, that is, when students choose to complete a task because they find it useful or relevant to their short- or long-term goals (Eccles and Wigfield 2020). When designing their instruction and assessment approach, instructors should be mindful of how these course components are viewed by students to increase their perceived utility-value and by extension, student engagement. This could involve providing an explanatory rationale statement at the beginning of assignments, or highlighting how the information will be useful in their future career when giving examples in online lectures.

Interestingly, emotional engagement decreased the most in $\mathrm{C} 2$ compared to $\mathrm{C} 1$ and it was the only regression analysis where engagement levels at $\mathrm{C} 1$ predicted $\mathrm{C} 2$. One reason for this finding could be that students' emotional engagement is related to course factors outside of instruction and assessment formats, including course content. Indeed, student interest is an important factor in determining their level of engagement (Kahu et al. 2017). Interest may be more prevalent when students enjoy the course content rather than when they feel forced to take mandatory courses they find little interest in, which could also impact their endorsement of MAP goals. One way to facilitate emotional engagement is through the use of humor. With that in mind, we turn to the work of McCabe et al. (2017), who discuss how humor can support the development of relationships with students and increase their learning. Nevertheless, future research is needed in this area to further explore additional course components to better understand the association between achievement goals and emotional engagement.

\subsection{Concerns with cheating and perceived success}

\subsubsection{Cheating}

Students' concerns about cheating in their courses in $\mathrm{C} 2$, were not related to their achievement goals, but rather predicted by the number of students in the course and their perceptions of cheating in $\mathrm{C} 1$. In short, the larger the course, the more 
concerned students were with cheating - and students who were concerned about cheating in a traditional learning condition remained concerned in remote learning conditions. One explanation for this finding is that larger classes are often more impersonal and anonymous (Cash et al. 2017), perhaps allowing students to believe that cheating will go unnoticed. To remedy this, instructors can draw on the relatedness aspects of basic psychological needs (Ryan and Deci 2017) to develop a sense of community within their courses regardless of class size. This can be accomplished through breaking the class to work on tasks online together or creating study group options via online platform. Moreover, Cueso (2007) suggests that larger courses have more frequent violations of academic integrity, including cheating. This could be related to feelings of anonymity, mentioned above, but it may also be simple probability: having larger courses increases the odds that there are more likely to be students who cheat present.

Students' concerns with cheating in $\mathrm{C} 1$ were also a significant predictor of their concerns with cheating at $\mathrm{C} 2$. This finding may speak to the assessment practices of the course. According to the International Centre for Academic Integrity (2020), $39 \%$ of undergraduate students admit to cheating on tests and $62 \%$ admit to cheating on written assignments. If instructors were simply changing assessment to a CR/ NCR system, the different assessment types may still warrant similar discrepancies in cheating behaviour and therefore, concerns with cheating would remain consistent. Contrary to this, our results show that students' concerns with cheating between $\mathrm{C} 1$ and $\mathrm{C} 2$ significantly increased. It seems that concerns with cheating exist regardless of whether or not specific normative grades are awarded. This provides an excellent opportunity for researchers and instructors to rethink summative assessment practices from a motivation perspective (Daniels et al. 2020).

\subsubsection{Success}

Students' feelings about their success in C2 were positively predicted by MAP and PAV goals in C2. Said differently, when students held goals to learn as much as possible and to avoid doing worse than other students, they perceived themselves as successful after the learning condition changed. This pairing of goals is particularly interesting because it suggests that success under the remote learning conditions came from both MAP goals and their intraindividual perspective on competence and PAV goals and their interindividual perspective on not losing to others. Without grades, it seemed that students had to look to other means for defining competence and the strongest indicators came from both approach and avoidance perspectives.

Similar to concerns with cheating, instructors could draw on the relatedness component of basic psychological needs (Ryan and Deci 2017). Building a sense of community in the course might alleviate some of the concern with losing to others, consistent with PAV goals. Moreover, two additional UDL guidelines can be implemented to support students in their perceptions of academic success (CAST 2018). Consistent with the notion of relatedness, the UDL guidelines highlight the importance of fostering collaboration and community within courses. Indeed, research by Sadera and colleagues (2009) found strong associations between learner interaction and engagement, sense of community and success in online learning. Moreover, the 
UDL guideline of increased mastery-oriented feedback, highlights that this type of feedback guides students towards mastery rather than performance goals (CAST 2018). Therefore, instructors when providing feedback to their students should be mindful that the feedback, is relevant, constructive, accessible, important and timely (CAST 2018).

\subsection{Limitations and future directions}

Although our findings provide important insights into the achievement goals of students under different instructional and assessment conditions, it is important to consider the following four limitations. First, participants represent a convenience sample of university students who utilized social media platforms and/or responded to email correspondence for their university. As such, these findings cannot generalize to other groups of students and post-secondary institutions. Rather, the results provide a snapshot of some students' experiences during the changes to assessment and instruction as a result of the COVID-19 pandemic. Nonetheless, the proximity of the research to their actual learning experiences may somewhat compensate for the narrow sample. Future research could strategically target students from specific faculties or expand data collection to additional postsecondary institutions.

Second, to capture students' perceptions of their learning condition the items focused students on both the changes to instruction (e.g., online) and assessment (e.g., CR/NCR). An important consideration when designing questionnaire items is to limit each question to one idea (Mertens 2014), however, instruction and assessment together authentically represent the learning condition that students experience. Balancing these perspectives, we felt students would be unable to separate their responses to specifically changes in instruction or assessment and instead combined the two in the survey instructions. Future research interested in examining changes to instruction and assessment will also have to balance the authenticity of the learning experience with the precision of questionnaire items and may decide to separate the domains to gain additional information on students' perspectives. Moreover, future research in this area should make the distinction between online learning and "emergency remote teaching" (Hodges et al. 2020). Online learning is designed to be remote from the beginning, with online assessment methods planned in advance. This could result in different outcomes for students' motivation, engagement and perceptions when compared to an abrupt change to instruction and assessment. This type of research will continue to emerge as researchers navigate the education impact of the COVID-19 pandemic.

Third, the data we collected were correlational and retrospective meaning that students provided answers in a single sitting for both their motivation, engagement and perceptions before changes to instruction and assessment were made and then again after. It is possible that responses to the "before" questions may be slightly more positive had they been collected in live time; however, the mean scores are actually quite similar to what is typically found in university samples. The opposite is also true, that students' responses to the "after" questions may be more negative because of their proximity to the "before" responses. Even if this were to be the case, 
the decreases were so marked and consistent that we believe the changes to instruction and assessment did have a clear uniformly negative association with motivation, engagement and perceptions of success. Despite these limitations, the information garnered is nonetheless important and increases our understanding of how the change to remote learning impacted university students' motivation, engagement and perceptions.

Finally, we utilized a single item to measure students' feelings of success and their concerns regarding cheating in their courses. While multi-item scales are often seen as more advantageous, there have been arguments made for the adequacy of single items in similar domains such as job satisfaction (e.g., Dolbier et al. 2005) or achievement emotions (Gogol et al. 2014). Nevertheless, future research could implement multi-item scales to measure these constructs so long as it did not increase participant fatigue and reduce participation.

\section{Conclusion}

The results of our study provide researchers and postsecondary institutions with valuable information about achievement goals related to instructional and assessment formats. This study provides a unique contribution to the growing research efforts in response to the COVID-19 pandemic that can support the development of policies and practices at postsecondary institutions moving forward. Moreover, this study further emphasizes the importance of MAP goals to support students' behavioural, emotional and cognitive engagement and feelings of success. Moreover, we provide several recommendations for instructors as they continue to design courses with student engagement, success and cheating in mind. This is particularly advantageous for instructors as postsecondary institutions continue to wrestle with how to deliver courses moving forward and abrupt changes to instructional and assessment practices may be required once again.

Funding Funding for this project was provided by the Faculty Of Education, Support For The Advancement Of Scholarship (SAS) Operating Grant and a Social Sciences and Humanities Research Council Grant (SSHRC \#435-2015-0216) award to the first author.

\section{Compliance with ethical standards}

Conflicts of interest Not applicable.

Availability of data and material Data available upon request.

\section{References}

Appleton, J. J., Christenson, S. L., \& Furlong, M. J. (2008). Student engagement with school: Critical conceptual and methodological issues of the construct. Psychology in the Schools, 45(5), 369-386. https://doi.org/10.1002/pits.20303. 
Cash, C. B., Letargo, J., Graether, S. P., \& Jacobs, S. R. (2017). An analysis of the perceptions and resources of large university classes. CBE Life Sciences Education. https://doi.org/10.1187/ cbe.16-01-0004.

CAST (2018). Universal design for learning guidelines version 2.2. http://udlguidelines.cast.org

Connell, J. P., \& Wellborn, J. G. (1991). Competence, autonomy and relatedness: A motivational analysis of self-system processes. In M. R. Gunnar \& L. A. Sroufe (Eds.), The Minnesota symposia on child psychology, Vol. 23. Self-processes and development (p. 43-77). Lawrence Erlbaum Associates, Inc.

Cuseo, J. (2007). The empirical case against large class size: Adverse effects on the teaching, learning and retention of first-year students. Journal of Faculty Development, 21, 5-21.

Daniels, L. M., Adams, C. \& McCaffrey, A. (2016). Emotional and Social Engagement in an xMOOC: The Case of Dino 101. In Sharon Tettegah \& M. P. McCreery (eds.). Emotions, Technology and Learning, pp 25-41.

Daniels, L. M., Haynes, T. L., Stupnisky, R. H., Perry, R. P., Newall, N., \& Pekrun, R. (2008). Individual differences in achievement goals: A longitudinal study of cognitive, emotional and achievement outcomes. Contemporary Educational Psychology, 33, 584-608. https://doi.org/10.1016/j.cedps ych.2007.08.002.

Daniels, L. M., Pelletier, G., Radil, A. I., \& Goegan, L. D. (2020). Motivating Assessment: How to Leverage Summative Assessments for the Good of Intrinsic Motivation. In Sharon Nichols \& Divya Varier (eds.). Theory to Practice: Educational Psychology for Teachers and Teaching (Teaching on Assessment).

Daumiller, M., \& Janke, S. (2019). The impact of performance goals on cheating depends on how performance is evaluated. AERA Open. https://doi.org/10.1177/2332858419894276.

Daumiller, M., Rinas, R., Olden, D., \& Dresel, M. (2020). Academics' motivations in professional training courses: Effects on learning engagement and learning gains. International Journal for Academic Development. https://doi.org/10.1080/1360144X.2020.1768396.

Dolbier, C. L., Webster, J. A., McCalister, K. T., Mallon, M. W., \& Steinhardt, M. A. (2005). Reliability and validity of a single-item measure of job satisfaction. American Journal of Health Promotion, 19(3), 194-198. https://doi.org/10.4278/0890-1171-19.3.194.

Eccles, J. S., \& Wigfield, A. (2020). From expectancy-value theory to situated expectancy-value theory: A developmental, social cognitive and sociocultural perspective on motivation. Contemporary Educational Psychology. https://doi.org/10.1016/j.cedpsych.2020.101859.

Elliot, A. J. (1999). Approach and avoidance motivation and achievement goals. Educational Psychologist, 34(3), 169-189. https://doi.org/10.1207/s15326985ep3403_3.

Elliot, A., McGregor, H., \& Gable, S. (1999). Achievement goals, study strategies and exam performance: A mediational analysis. Journal of Educational Psychology, 91, 549-563. https://doi. org/10.1037/0022-0663.91.3.549.

Elliot, A. J., \& Murayama, K. (2008). On the measurement of achievement goals: Critique, illustration and application. Journal of Educational Psychology, 100(3), 613-628. https://doi. org/10.1037/0022-0663.100.3.613.

Fredricks, J. A., Blumenfeld, P. C., \& Paris, A. H. (2004). School engagement: Potential of the concept, state of the evidence. Review of Educational Research, 74(1), 59-109. https://doi.org/10.3102/00346 543074001059.

Fung, N. (2020, April 1). Universities differ on whether a pass-fail grading scheme should be optional. University Affairs. https://www.universityaffairs.ca/news/news-article/universities-differ-on-wheth er-a-pass-fail-grading-scheme-should-be-optional/

Goegan, L. D., \& Daniels, L. M. (2019). Academic success for students in postsecondary education: The role of student characteristics and integration. Journal of College Student Retention: Research, Theory \& Practice. https://doi.org/10.1177/1521025119866689.

Gogol, K., Brunner, M., Goetz, T., Martin, R., Ugen, S., Keller, U., et al. (2014). "My questionnaire is too long!" The assessments of motivational-affective constructs with three-item and single-item measures. Contemporary Educational Psychology, 39(3), 188-205. https://doi.org/10.1016/j.cedps ych.2014.04.002.

Gonida, E. N., Voulala, K., \& Kiosseoglou, G. (2009). Students' achievement goal orientations and their behavioral and emotional engagement: Co-examining the role of perceived school goal structures and parent goals during adolescence. Learning and Individual Differences, 19(1), 53-60. https://doi. org/10.1016/j.lindif.2008.04.002. 
Hodges, C., Moore, S., Lockee, B., Trust, T., \& Bond, A. (2020). The difference between emergency remote teaching and online learning. Educause Review, 27. https://medicine.hofstra.edu/pdf/faculty/ facdev/facdev-article.pdf

Huang, C. (2012). Discriminant and criterion-related validity of achievement goals in predicting academic achievement: A meta-analysis. Journal of Educational Psychology, 104(1), 48-73. https:// doi.org/10.1037/a0026223.

Hyslop, K. (2020, June 22). What's University Going to Look Like This Fall? A look at UBC's choices and challenges could offer insights into post-secondary education in a prolonged pandemic. The Tyee, https://thetyee.ca/News/2020/06/22/University-Fall-Covid-Return/

International Centre for Academic Integrity (2020). https://www.academicintegrity.org/statistics/

Jang, H., Kim, E. J., \& Reeve, J. (2016). Why students become more engaged or more disengaged during the semester: A self-determination theory dual-process model. Learning and Instruction, 43, 27-38. https://doi.org/10.1016/j.learninstruc.2016.01.002.

Kahu, E., Nelson, K., \& Picton, C. (2017). Student interest as a key driver of engagement for first year students. Student Success, 8(2), 55-66. https://studentsuccessjournal.org/article/view/504

King, D. L., \& Case, C. J. (2014). E-cheating: incidence and trends among college students. Issues in Information Systems, 15(1), 20-27. https://iacis.org/iis/2014/4_iis_2014_20-27.pdf

Lounsbury, J. W., Fisher, L. A., Levy, J. J., \& Welsh, D. P. (2009). An investigation of character strengths in relation to the academic success of college students. Individual Differences Research, 7, 52-69.

McCabe, C., Sprute, K., \& Underdown, K. (2017). Laughter to learning: How humor can build relationships and increase learning in the online classroom. Journal of Instructional Research, 6, 4-7. https ://files.eric.ed.gov/fulltext/EJ1152964.pdf

Meece, J. L., Blumenfeld, P. C., \& Hoyle, R. H. (1988). Students' goal orientations and cognitive engagement in classroom activities. Journal of educational psychology, 80(4), 514-523.

Mertens, D. M. (2014). Research and evaluation in education and psychology: Integrating diversity with quantitative, qualitative and mixed methods. New York: Sage publications.

Miller, A., \& Young-Jones, A. D. (2012). Academic integrity: Online classes compared to face-to-face classes. Journal of Instructional Psychology, 39(3), 138-145.

Murdock, T. B., \& Anderman, E. M. (2006). Motivational perspectives on student cheating: Toward an integrated model of academic dishonesty. Educational Psychologist, 41, 129-145. https://doi. org/10.1207/s15326985ep4103_1.

Murdock, T. B., Hale, N. M., \& Weber, M. J. (2001). Predictors of cheating among early adolescents: Academic and social motivations. Contemporary Educational Psychology, 26, 96-115. https://doi. org/10.1006/ceps.2000.1046.

Niya, Y., Ballantyne, R., North, M. S., \& Crocker, J. (2008). Gender, contingencies of self-worth and achievement goals as predictors of academic cheating in a controlled laboratory setting. Basic and Applied Social Psychology, 30, 76-83. https://doi.org/10.1080/01973530701866656.

Pulfrey, C. J., Vansteenkiste, M., \& Michou, A. (2019). Under pressure to achieve? The impact of type and style of task instructions on student cheating. Frontiers in Psychology, 10, 1-18. https://doi. org/10.3389/fpsyg.2019.01624.

Rawsthorne, L. J., \& Elliot, A. J. (1999). Achievement goals and intrinsic motivation: A meta-analytic review. Personality and Social Psychology Review, 3(4), 326-344. https://doi.org/10.1207/s1532 7957pspr0304_3.

Ryan, R. M., \& Deci, E. L. (2017). Self-determination theory: Basic psychological needs in motivation development and wellness. New York: Guilford Publishing.

Sadera, W. A., Robertson, J., Song, L., \& Midon, M. N. (2009). The role of community in online learning success. Journal of Online Learning and Teaching, 5(2), 277-284. https://pdfs.semanticscholar.org/ f2a6/a457ecc995758fd2fd4ecf4fd72547c52e5b.pdf

Senko, C., \& Dawson, B. (2017). Performance-approach goal effects depend on how they are defined: Meta-analytic evidence from multiple educational outcomes. Journal of Educational Psychology, 109(4), 574-598. https://doi.org/10.1037/edu0000160.

Shih, S. S. (2008). The relation of self-determination and achievement goals to Taiwanese eighth graders' behavioral and emotional engagement in schoolwork. The Elementary School Journal, 108(4), 313-334. https://doi.org/10.1086/528974.

Sideridis, G. D., \& Kaplan, A. (2011). Achievement goals and persistence across tasks: The roles of failure and success. The Journal of Experimental Education, 79(4), 429-451. https://doi. org/10.1080/00220973.2010.539634. 
Sun, J. C. Y., \& Rueda, R. (2012). Situational interest, computer self-efficacy and self-regulation: Their impact on student engagement in distance education. British Journal of Educational Technology, 43(2), 191-204. https://doi.org/10.1111/j.1467-8535.2010.01157.x.

Van Yperen, N. W., Blaga, M., \& Postmes, T. (2014). A meta-analysis of self-reported achievement goals and nonself-report performance across three achievement domains (work, sports and education). PLoS ONE. https://doi.org/10.1371/journal.pone.0093594.

Van Yperen, N. W., Hamstra, M. R., \& van der Klauw, M. (2011). To win, or not to lose, at any cost: The impact of achievement goals on cheating. British Journal of Management, 22, S5-S15. https://doi. org/10.1111/j.1467-8551.2010.00702.x.

Watson, G. R., \& Sottile, J. (2010). Cheating in the digital age: Do students cheat more in online courses?. Online Journal of Distance Learning Administration, 13(1). https://mds.marshall.edu/cgi/ viewcontent.cgi?article $=1000 \&$ context $=$ eft_faculty

York, T. T., Gibson, C., \& Rankin, S. (2015). Defining and measuring academic success. Practical Assessment, Research \& Evaluation, 20(5), 1-20. http://www.pareonline.net/getvn.asp?v=20\&n=5

Yüksel, H. S., \& Gündüz, N. (2017). Formative and summative assessment in higher education: opinions and practices of instructors. European Journal of Education Studies, 3(8), 336-356. https://oapub .org/edu/index.php/ejes/article/view/904

Publisher's Note Springer Nature remains neutral with regard to jurisdictional claims in published maps and institutional affiliations.

Lia M. Daniels is a Professor of Educational Psychology at the University of Alberta. She studies student and teacher motivation and emotions across all levels of schooling with the intention of creating supporting learning environments.

Lauren D. Goegan is a Postdoctoral Fellow in Educational Psychology at the University of Alberta. She studies the transition from high school to postsecondary education, with a focus on students with Learning Disabilities. Her research interests also include examining student motivation, academic success and academic dishonesty.

Patti C. Parker is a Postdoctoral Fellow in Educational Psychology at the University of Alberta. Her research interests include examining the impact of motivation treatments on individuals' achievement and psychosocial well-being across university, health and sport settings. 